\title{
Professor Jan Epsztajn
}

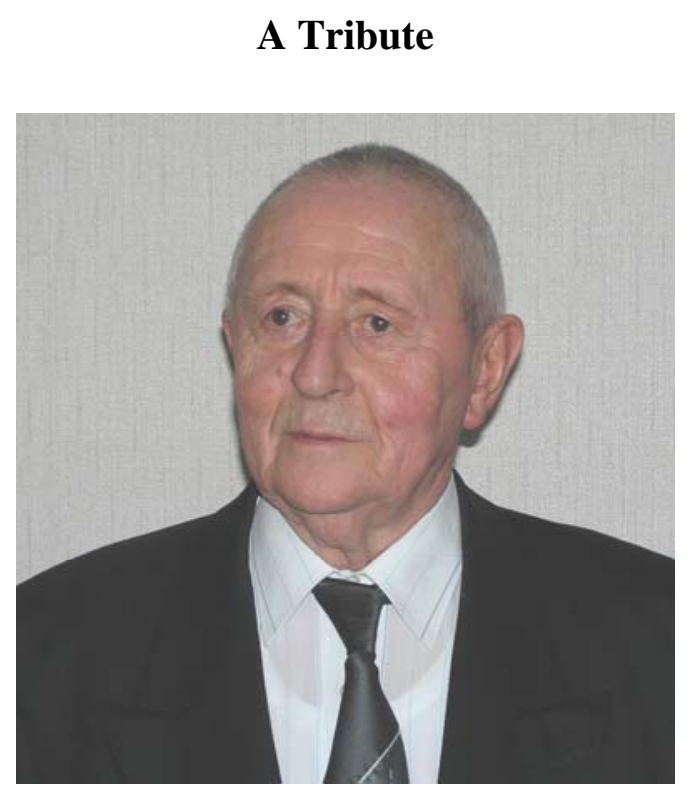

Jan Epsztajn was born in Łódź (Poland) on November 28, 1932. He obtained his M.Sc. degree at the Technical University of Łódź (Politechnika Łódzka) in 1957 under the supervision of Professor Jan Michalski. He then worked for two years for the chemical industry. In 1959 he moved to the University of Łódź (Uniwersytet Lódzki) and joined the group of Professor Witold E. Hahn. In 1963 he received his Ph.D. degree and was appointed Assistant Professor at the University of Łódź. With the permission of the University he also worked part-time for the pharmaceutical industry.

Twice, with sabbaticals (1968/69 and 1975), he carried out research at the University of East Anglia (Norwich, UK) in the research group of Professor Alan R. Katritzky. He was engaged in studies related to the synthesis of $\mathrm{N}$-amino species and their conversion into $\mathrm{N}-\mathrm{N}-\mathrm{NO}_{2}$ aromatic heterocycles as well as aliphatic systems.

After his return and completion of the habilitation thesis in 1977, he received his D.Sc. degree and was appointed Associate Professor at the University of Łódź where in 1988 he was promoted to the position of full Professor.

His scientific interest was initially oriented towards applications of the Mannich Reaction in the synthesis of heterocyclic compounds and at the same time he was also involved in a study of the reactivity of pyridocycloalkenes in their relation to alkylpyridines. Part of this study was carried out in cooperation with Professor Hubertus Ahlbrecht and Dr. Hans-Otto Kalinowski from the Justus Liebig University in Giessen (Germany). This research was concerned with the conformational analysis of cycloalkenes fused with aromatic species.

In Poland he pioneered research on the applications of ortho-metallation (lithiation) as a methodology for the preparation of heterocyclic systems fused with aromatic and heteroaromatic rings. The essential examples of this activity were as follows: regioselective construction of 
phthalides, isoindolinones, isocoumarines, isocoumarones as well their aza-analogues and a general procedure for aza-anthraquinones systems. The list of selected publications of Professor Jan Epsztajn illustrates the scope of his chemical interests.

Professor Jan Epsztajn has received several distinctions for his contributions to chemistry.

Professor Jan Epsztajn has served the chemical community for many years. Along with his direct scientific activity, he was promoter and motivator of various important events.

Professor Jan Epsztajn is always friendly and with a remarkable sensitivity he listens and helps not necessarily in relation to work. It has been a great honor and pleasure for me to write this tribute.

I give below his contact address:

Prof. Jan Epsztajn

Department of Organic Chemistry

University of Łódź

Narutowicza 68,

90-136 Łódź

Poland

E-mail:epsztajn@uni.lodz.pl

Andrzej Jóźwiak

\section{Selected Publications of Professor Jan Epsztajn}

1. O wyzyskaniu reakcji Mannicha do syntezy układów heterocyklicznych. II. Pochodne kwasu (-2,3,4,5-czterohydro-1,2,4,-triazynylo-4)-octowego (Application of Mannich Reaction for Synthesis of Heterocyclic Systems. Part II. (2,3,4,5-Tetrahydro-1,2,4-triazinyl4)-acetic Acid Derivatives) Hahn, W. H.; Epsztajn, J. Rocz. Chem. 1961, 35, 907.

2. Cykloparafiny skondensowane z pierścieniami heterocyklicznymi. III. Synteza cyklicznych analogów $\alpha$-winylopirydyn (Cycloparaffins Conjugated with Heterocyclic Rings. Part III. Synthesis of Cyclic Analogues of $\alpha$-Vinylpyridines) Hahn W. H.; Epsztajn, J. Rocz. Chem. 1964, 38, 989.

3. Pochodne benzo[4,5]azepiny (Benz[4,5]azepine derivatives) Hahn, W. H.; Epsztajn, J.; Madeja-Kotkowska, Z. Rocz. Chem. 1965, 39, 1423.

4. Cykloparafiny skondensowane z pierścieniami heterocyklicznymi. XV. Reakcja aldehydów aromatycznych z 6-metylo-2,3-cykloalkenopirydynami (Cycloparaffins Conjugated with Heterocyclic Rings. Part XV. Reaction of Aromatic Aldehydes with 6-Methyl-2,3cycloalkenpyridines) Epsztajn, J.; Hahn, W. E.; Tosik, B. K. Rocz. Chem. 1969, 43, 807.

5. Amine-nitroimides: a New Functional GroupEpsztajn, J; Katritzky, A. R. Tetrahedron Lett. 1969, 10, 4739. 
6. N-Oxides and Related Compounds-XXXIX; Some Reactions of 1-Aminopyridinium Salts Epsztajn, J.; Lunt, E; Katritzky, A. R. Tetrahedron 1970, 26, 1665.

7. Lithiation of Pyrido[b]cycloalkenes with Phenyllithium Epsztajn, J.: Bieniek, A.; Brzeziński, J. Z. Bull. Acad. Pol. Sci., Ser.Sci. Chim. 1975, 23, 917.

8. Allylic and Benzylic Deamination by Thermal Cleavage of 1-Substituted 1,2-dihydro-2,4,6triphenylpyridines Bulton, A. J.; Epsztajn, J.; Katritzky, A. R.; Nie, P.-L. Tetrahedron Lett. 1976, 17, 2689.

9. Lithiation of The Cycloalkeno[b]quinolines by Phenyllithium Brzeziński, J. Z.; Epsztan, J.; Michalski, T. J. Tetrahedron Lett. 1976, 17, 4635.

10. N-Oxides and Related Compounds. Part 58. Some Precursors of Pyridinum Methylide Bapat, J. B.; Epsztajn, J.; Katritzky, A. R.; Plau, B. J. Chem. Soc., Perkin Trans. 1 1977, 1692.

11. Reactions of the N,N-dialkylpyridylcarboxylic Amides with Lithium Amides. Regioselective Lithiation of N,N-diisopropyl-pyridylcarboxylic Amides, A Useful Method for Synthesis of 2,3- and 3,4-Disubstituted Pyridines Epsztajn, J.; Berski, Z.; Brzeziński J. Z.; Jóźwiak, A. Tetrahedron Lett. 1980, 21, 4739.

12. The Dual Behaviour of N,N-Dialkylpyridylcarboxylic Amides in the Reaction with Lithium Diisopropylamide Epsztajn, J.; Bieniek, A.; Brzeziński J. Z.; Jóźwiak, A. Tetrahedron Letters 1983, 24, 4735.

13. Delocalisation, Conformation and Basicity of Anilines Ahlbrecht, H.; Düber, E. O.; Epsztajn, J.; Marcinkowski, R. M. K. Tetrahedron 1984, 40, 1157.

14. The Conformational Analysis of Benzocycloalkanones Using the Lanthanide Induced Shift Method Epsztan, J.; Bieniek, A.; Brzeziński, J. Z.; Kalinowski, H.-O. Tetrahedron 1986, 42, 3559.

15. Applications of Organolithium and Related Reagents in Synthesis, Part 7. Synthesis and Metallation of 4-Methoxypicolin- and 2-Methoxyisonicotinanilides. A Useful Method for Preparatoin of 2,3,4,-trisubstisutes pyridines Epsztajn, J.; Bieniek, A.; Płotka, M. W., Suwald, K. Tetrahedron 1989, 45, 7469.

16. Applications of Organolithium and Related Reagents in Synthesis, Part VI. A General Study of the Lithiation of Secondery Picoline- and Isonicotine Amides Epsztajn, J.; Jóźwiak, A.; Czech, K.; Szcześniak, A. K., Monatsh. Chem. 1990, 121, 909.

17. Applications of Organolithium and Related Reagents in Synthesis, Part 9. Synthesis and Metallation of 4-Chloropicolin- and 2-Chloroisonicotinanilides. A Useful Method for Preparation of 2,3,4,-Trisubstisutes Pyridines Epsztajn, J.; Bieniek A.; Kowalska, J. A. Tetrahedron 1991, 47, 1697.

18. Applications of Organolithium and Related Reagents in Synthesis, Part 11. Metallation of 2Methyl- and 4-Methylisonicotin acids. A Useful Method for Preparation of Azaisocoumarins Epsztajn, J.; Płotka, M. W.; Ścianowski, J. Synth. Commun. 1992, 22, 1239.

19. Applications of Organolithium and Related Reagents in Synthesis.Part 14. Synthetic Strategies Based on Aromatic Metallation. A Concise Regiospecific Conversion of Benzoic 
Acids into Their ortho-Pyridoyl Derivatives Epsztajn, J.; Jóźwiak, A.; Krysiak, J. A. Tetrahedron 1994, 50, 2907.

20. Applications of Organolithium and Related Reagents in Synthesis. Part 15. A Concise Regiospecific Conversion of Picolinic- and Isonicotinic Acids into 2-Benzoyl- and 4Benzoylnicotinic Acids Epsztajn, J.; Jóźwiak, A; Szcześniak, A. K. Synth. Commun. 1994, 24, 1789.

21. Application of Organolithium and Related Reagents in Synthesis XVI: Synthetic Strategies Based on Aromatic Metallation. A Concise Regiospecific Conversion of Chlorobenzoic Acids into their Benzylated Derivatives Epsztajn, J.; Bieniek, A.; Kowalska, J. A. Monatsh. Chem. 1996, 127, 701.

22. Application of Organolithium and Related Reagents in Synthesis; Part 17: Synthesis of Azaisoindolo[2,1-a]quinoline Derivatives Epsztajn, J.; Grzelak, R.; Jóźwiak, A. Synthesis 1996, 1212.

23. Application of Organolithium and Related Reagents in Synthesis. Part 18. Synthetic Strategies Based on Aromatic Metallation. A Conversion of Methyl ortho-pyridoylbenzoates into Aza-anthra-5,10-quinones Epsztajn, J.; Jóźwiak, A.; Krysiak, J. K.; Łucka, D. Tetrahedron 1996, 52, 11025.

24. Application of Organolithium and Related Reagents in Synthesis. Part 21. Synthetic Strategies Based on ortho-Aromatic Metallation. A Concise Regiospecific Synthesis of Arylnaphthalanes as Precursors of Naphthylisoquinoline Alkaloids Epsztajn, J.; Jóźwiak, A.; Szcześniak, A. K. J. Chem. Soc., Perkin Trans. 1 1998, 2563.

25. Application of Organolithium and Related Reagents in Synthesis. Part 23: Synthetic Strategies Based on ortho-Aromatic Metallation. Synthesis of 4b-Arylisoindolo[2,1a]quinoline derivatives Epsztajn, J.; Jóźwiak, A.; Kołuda, P.; Sadokierska, I.; Wilkowska, I. D. Tetrahedron 2000, 56, 4837.

26. Application of Organolithium and Related Reagents in Synthesis, Part 24. Synthetic Strategies Based on Aromatic Metallation. A Concise Regiospecific Conversion of Benzoic Acids into 2-(1-Aryl-2-methoxycarbonilethyl)benzoic Acids Epsztajn, J.; Bieniek, A.; Kowalska, J. A.; Kulikiewicz, K. K. Synthesis 2000, 1603.

27. Application of Organolithium and Related Reagents in Synthesis. Part 25: Novel Specific Synthesis of the 4-Arylisochroman-3-acetic Acids via Conversion of Benzoic Acids Bieniek, A.; Epsztajn, J.; Kowalska, J.; Malinowski, Z. Tetrahedron Lett. 2001, 42, 9293.

28. Application of Organolithium and Related Reagents in Synthesis; Part 26. Synthetic Strategies Based on Directed ortho-Aromatic Metallation: Synthesis of 4-Methyl-2Hphthalazin-1-ones Epsztajn, J.; Malinowski, Z.; Brzeziński, J. Z.; Karzatka, M. Synthesis 2001, 2085.

29. Application of Organolithium and Related Reagents in Synthesis, Part 29. A Concise Regiospecific Conversion of Benzoic Acids into 5-(2-Carboxyphenyl)-5-phenylpent-2-enoic acids Bieniek, A.; Epsztajn, J.; Kulikiewicz, K. K. Monatsh. Chem. 2004, 135, 69. 
30. Behaviour of $N$-Pyridylbenzamides versus Benzanilides in the ortho-Directed Lithiation of Masked Aromatic Carboxylic Acids Jóźwiak, A.; Brzeziński, J. Z.; Płotka, M. W.; Szcześniak, A. K.; Malinowski, Z.; Epsztajn, J. Eur. J. Org. Chem. 2004, 3254. 